\title{
KEBERHASILAN SEKOLAH MERAIH GELAR ADIWIYATA DAPAT MENINGKATKAN KESADARAN RAMAH LINGKUNGAN SISWA DALAM HEMAT ENERGY \\ Study Case: SMA Negeri 8 Serang Banten \\ Colaboration Research
}

\author{
Indriyani Rachman, Samsul Muarif, Edy Santuso, Ida Rahayu dan Karlina Puspa Dahlia, \\ Slamet Raharjo, Toru Matsumoto \\ Universitas Syeh Islam, SMAN 8 Kota Serang, SMAN 8 Kota Serang, SMAN 8 Kota Serang, \\ Universitas Andalas Padang, The University of Kitakyusu \\ destyn_liza@yahoo.com.sg, samsu1922@gmail.com, edysantuso@gmail.com, \\ ida.lukman@gmail.com,sraharjo@ft.unand.ac.id,matsumoto-t@kitakyu-u.ac.jp
}

\begin{abstract}
One of the school's successes in reaching the title Adiwiyata is habitual school community in everyday life. These habits reflect whether they are environmentally friendly patterned or not. Adiwiyata is a program that forms the entire school community to characters that care for the environment. Creating a school that is clean, healthy, beautiful and ethics and aesthetics. With the knowledge and habits of students' awareness and eco-friendly lifestyle, it is the foundation for SMA Negeri 8 Kota Serang to be earned Adiwiyata. This study raised the issue of whether the program launched by the school for a degree Adiwiyata can increase knowledge and change the habits of students in energy efficiency. This research method using qualitative description, in which respondents were given questionnaires, interviews, and observations. However, the role that the school community is very important in realizing the success of the school to achieve Adiwiyata title. Thus the required environmental education activities that can form the students become the generation that can contribute to being part minded citizens who are environmentally.
\end{abstract}

Keywords: Adiwiyata, Environmental Education, Sustainable

\section{A. PENDAhULUAN}

Adiwiyata Program ini merupakan program yang digulirkan oleh Kementerian Lingkungan hidup Republik Indonesia yang bekerjasama dengan Kementerian pendidikan dan Kebudayaan. Melalui kegiatan ini, diharapkan dapat menciptakan kondisi yang baik bagi sekolah sehinggadapat menjadi tempat yang nyaman dan kondusif selama proses pembelajaran dan penyadaran warga sekolah, dengan harapan dikemudian hari warga sekolah tersebut dapat turut bertanggungjawab dalam segala bentuk upaya penyelamatan lingkungan hidup dan pembangunan yang berkelanjutan. Program ini sering kali terhambat karena kurangnya sosialisasi terhadap warga sekolah akan tahapantahapan yang harus dilakukan demi terciptanya sekolah berwawasan lingkungan. Bukan hanya sebuah perencanaan yang baik, namun juga kegiatan ini harus diimbangi dengan realisasi dalam kesehariannya. Untuk itu, dalam hal ini guru sebagai panutan diharapkan dapat menjadi motor yang baik guna mendorong siswa merubah pandangan dan pola pikir mereka dalam aktifitas ramah lingkungan.

Ada 31 Aspek penilaian Program Adiwiyata, seluruh aspek tersebut menjadi point penting dalam penentuan apakah sekolah tersebut dapat menjadi sekolah Adiwiyata atau tidak. Tentunya dengan berbagai tingkatan yang disesuaikan dengan hasil penilaian. Salah satu hal yang ikut menentukan adalah, pengetahuan siswa dan 
kebiasaan siswa dalam kehidupan seharihari.

Siswa SMA Negeri 8 Serang pada dasarnya para siswa sudah memiliki kebiasaan dan pengetahuan tentang ramah lingkungan dalam bentuk penghematan energy. Kebiasaan dan pengetahuan mereka menghemat energy merupakan salah satu bentuk kesadaran siswa terhadap ramah lingkungan. Ini dapat juga menjadi dasar penilaian program Adiwiyata, pada point warga sekolah berwawasan ramah lingkungan.

Data terakhir yang dipublikasikan BLHD Provinsi Banten melalui websitenya menyatakan sampai dengan tahun 2014, Sekolah Adiwiyata di Provinsi Banten sudah mendapatkan penghargaan Adiwiyata baik dari tingkat provinsi maupun tingkat pusat yaitu: 5 Sekolah Adiwiyata Mandiri, 17 Sekolah Adiwiyata tingkat Nasional dan 37 Sekolah Adiwiyata tingkat Provinsi termasuk diantaranya 12 sekolah yang diusulkan ketingkat nasional.

Usia sekolah bukanlah menjadi patokan akan keberhasilan dapat menjadi sekolah yang ramah lingkungan dengan mencapai gelar Adiwiyata, seperti sekolah SMA Negeri 6 Padang, adalah sekolah yang terhitung sangat muda. Dengan jumlah murid 360 siswa pada tahun 2016. Sekolah ini dalam waktu 6 tahun dapat menjadi sekolah yang diperhitungkan di Kota Padang. Mendapat gelar Adiwiyata Mandiri dalam waktu 6 tahun. Berkat keuletan Kepala sekolah, Guru, siswa, orang tua murid dan staf. SMA Negeri 6 Padang ini terdapat dikawasan Mata Air Padang dengan luas area 15.000 M2, dengan luas bangunan $3.600 \mathrm{M} 2$. Ketika berdiri pada tahun 2008, SMA ini merupakan sekolah dengan predikat Adiwiyata Mandiri pada tahun 2016. Maka bukanlah hal yang sulit bagi SMA Negeri 8 Serang, bila bertekad agar menjadi sekolah peraih Program Adiwiyata.

SMA Negeri 8 Kota Serang merupakan sekolah yang terhitung masih sangat muda, tetapi seluruh warga sekolah berusaha berperan untuk dapat meraih gelar
Adiwiyata. Saat ini SMA Negeri 8 Serang belum pernah meraih gelas Adiwiyata, baik untuk tingkat kota maupun tingat Provinsi. Tetapi sedang mulai menata agar dapat terwujud.

Penelitian ini mengangkat masalah tentang apakah program-program yang dicanangkan sekolah dalam rangka meraih gelar adiwiyata dapat meningkatkan pengetahuan dan membawa perubahan kebiasaan siswa dalam kehidupan sehari-hari yang ramah lingkungan terutama masalah penghematan energi.

Pada dasarnya meraih gelar Adiwiyata merupakan motivasi pencapaian, tetapi hal intinya adalah adanya perubahan pada siswa mengenai perubahan pola hidup siswa menjadi lebih ramah lingkungan. Tentunya ini dipacu oleh program-program yang dilakukan dan tertera pada program Adiwiyata.

Untuk dapat mencapai tujuan tersebut, team Adiwiyata SMA Negeri 8 Serang, memiliki program-program yang berkaitan dengan pembelajaran mengenai pendidikan lingkungan hidup.

\section{B. KAJIAN LITERATUR}

Dalam jurnal yang di tulis oleh Reni Indrawati dengan judul Implementasi Pendidikan Karakter pada program Adiwiyata Melalui Kegiatan Lingkungan Berbasis Partisipatif di SMK negeri 1 Turen. Menuliskan teori menurut Soerjani (2009:52) Pendidikan Lingkungan Hidup (PLH) merupakan program Pendidikan untuk membina siswa agar memiliki pengertian, kesadaran, sikap, perilaku yang rasional serta bertanggung jawab terhadap alam dan terlaksanakannya pembangunan yang berkelanjutan melalui program sekolah yang biasa disebut dengan program Adiwiyata.

Penelitian yang dilakukan oleh Simsekli (2010: 1-9) dengan judul The Original Activities for Environmental Education and Their Effects on Students 
(A Case Study in Bursa). Penelitian ini meneliti efek dari pendidikan lingkungan melalui kegiatan pengembangan kesadaran lingkungan anak-anak. Siswa diberi pendidikan lingkungan dengan siswa melakukan beberapa kegiatan yang memang merupakan kegiatan kesehariannya. Dalam kegiatan pembelajaran siswa memberi jawaban terhadap pertanyaan-pertanyaan terbuka yang ditujukan pada awal danakhir penelitian, siswa membuat makalah yang berisi kegiatan yang merekalakukan dan mereka melaporkan kegiatan yang telah mereka pelajari. Hasil penelitian menunjukkan bahwa dalamsiswa tertarik dalam pembelajaran lingkungan dengan melakukan kegiatan yang tidak dibuat-buat atau ditekan olehguru, siswa tertarik dalam kegiatan yang berhubungan dengan lingkungan.

Pada jurnal yang ditulis oleh Yanti Dwi Rahmah dan Sjamsiar Sjamsuddin Indradi, Riyanto. Universitas Brawijaya yang berjudul Implementasi Program Sekolah Adiwiyata (Studi Pada SDN Manukan Kulon III/540 Kota Surabaya) penelitian ini menggunakanmetode kualitatif dengan pendekatan deskriptif. Penelitian ini menunjukkan bahwa sekolah tersebut lolos dalam seleksi tahap kota namun tahap selanjutnya mengalami ketidak berhasilan dalam mencapai penghargaan Adiwiyata. Hasil penelitian menunjukkan bahwa terdapat empat program yang diterapkan yaitu komposter, takakura, pembibitan, dan program 4R. Program tersebut diterapkan berdasarkan komponen antara lain kebijakan berwawasan lingkungan, pelaksanaa kurikulumberbasis lingkungan, kegiatan lingkungan berbasis partisipatif dan pengelolaan sarana pendukung ramah lingkungan.

Penerapan program tersebut terdapat faktor pendukung internal yakni SDM yang mumpuni dan adanya visi, misi, fungsi serta pengelolaan anggaran yang baik. Faktor pendukung eksternal adanya pihak wali murid dan pemberian BOSDA. Tetapi tenaga pendidik yangkurang kompak dan faktor penghambat eksternal adalah adanya renovasi gedung yang membuat ketidakberhasilan dalammencapai penghargaan Adiwiyata.

Menurut Ida Rianawaty dalam tulisannya di KOMPAS (05 Nov 2012) menyatakan bahwa Mewujudkan sekolah berwawasan lingkungan merupakan komitmen sekolah secara sistematis yang mengembangkan program-program untuk menginternalisasikan nilai-nilai lingkungan ke dalam seluruh aktifitas sekolah. Tampilan fisik sekolah ditata secara ekologis sehingga menjadi wahana pembelajaran bagi seluruh warga sekolah untuk bersikap arif dan berprilaku ramah lingkungan. Pemberian pengetahuan dan pembentukan kesadaran tentang perilaku hidup bersih dan sehat dirasa sangat efektif ketika dilakukan pada siswa sejak di bangku sekolah dasar. Lingkungan Sekolah yang kondusif sangat diperlukan agar tercipta proses pembelajaran yang bermutu.

\section{METODOLOGI PENELITIAN}

Penelitian ini merupakan penelitian kualitatif, dengan mengambil 2 tema data melalui angket, wawancara, dan pengamatan. Penyebaran angket kepada siswa berdasarkan isi materi program kerja team Adiwiyata SMA Negeri 8. Program kerja sekolah meliputi pengetahuan, Attitude, behavior siswa mengenai ramah lingkungan. Yaitu kebiasaan siswa dalam penggunaan energi baik di sekolah ataupun di rumah. Program berikutnya adalah sekolah bekerjasama dengan seluruh team mengajak seluruh masyarakat sekolah dan orang tua, untuk berperan aktif dalam kebersihan dan penghijauan sekolah.

Untuk pengambilan data penelitian ini disebarkan angket dalam dua tahap.

1. Tahap pertama adalah secara random kepada siswa. Dengan jumlah responden 50 orang siswa yang terdiri dari: 25siswa kelas $\mathrm{X}, 15$ siswa kelas XI, dan 10 siswa kelas 
XII. Angket ke 1 terbagi atas 3 lembar pertanyaan. Angket ini disebar setelah team Adiwiyata melaksanakan beberapa program untuk mencapai gelar Adiwiyata.

1.1.Mengukur pengetahuan siswa tentang Program Adiwiyata.

1.2.Mengukur kebiasaan siswa pada saat ini berkaitan dengan ramah lingkungan.

1.3.Mengukur kemampuan siswa untuk masa yang akan datang.penyebaran angket tentang pengetahuan dan kebiasaan siswa berkaitan dengan pola hidup sehari-hari yang ramah lingkungan.

2. Tahap kedua kepada 192 siswa SMA Negeri 8 Serang, yang tersebar di 6 kelas. Seperti yang tertera pada tabel dibawah ini:

Tabel 1

Distribusi Penyebaran Angket

\begin{tabular}{|c|c|}
\hline Kelas & $\begin{array}{c}\text { Total } \\
\text { Responden }\end{array}$ \\
\hline X - 4 & 32 \\
\hline X - 6 & 40 \\
\hline XI - IPA 1 & 29 \\
\hline XI - IPA 2 & 29 \\
\hline XII - IPA 1 & 29 \\
\hline XII - IPA 2 & 33 \\
\hline Grand Total & 192 \\
\hline
\end{tabular}

3. Sementara wawancara dilakukan terhadap 3 orang siswa yang dipilih secara random, hal ini dilakukan guna mendapatkan data tentang pandangan siswa terkait dengan pengetahuan tentang lingkungan hidup dan pemikiran jangka pendek dan jangka panjang yang dapat menunjang terciptanya sekolah berwawasan lingkungan.
Tabel 2

Pertanyaan angket tahap 2

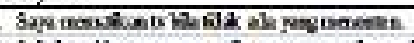

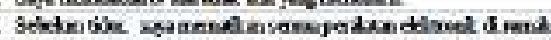

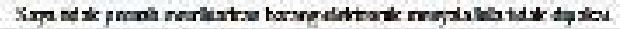

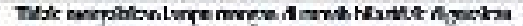

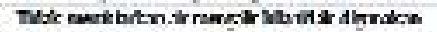

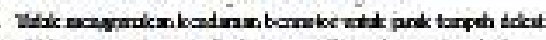

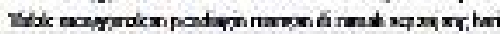

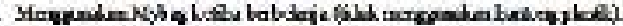

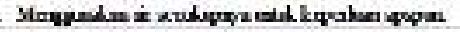

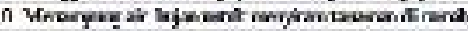

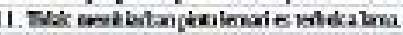

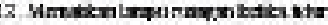

\section{HASIL DAN PEMBAHASAN}

\section{Profil Kota Serang.}

Kota Serang adalah ibu kota Provinsi Banten, Indonesia. Kota ini berada di bagian utara Provinsi Banten, serta dikelilingi oleh Kabupaten Serang di sebelah selatan, barat, dan timur, dan Laut Jawa di sebelah utara. Kota Serang dilintasi jalan tol lintas Jakarta-Merak.

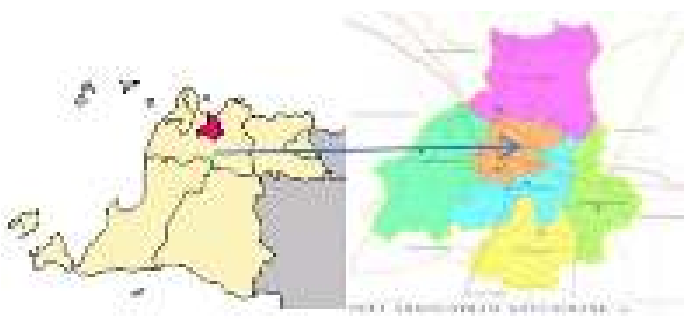

Gambar 1

Peta Provinsi Banten dan Kota Serang

Kota Serang terdiri atas 6 kecamatan, yang dibagi lagi atas sejumlah kelurahan. Dahulu Serang merupakan bagian dari wilayah Kabupaten Serang, kemudian ditetapkan sebagai kota otonom pada tanggal 2 November 2007. Kecamatan di kota Serang terdiri atas:Serang,Cipocok Jaya, Curug, Kasemen, Taktakan dan Walantaka.Kota Serang memiliki luas wilayah $266,77 \mathrm{~km}$ ' dengan jumlah penduduk sekitar 618802 jiwa. SMA Negeri 8 Kota Serang memiliki jumlah siswa 627 yang tersebar menjadi 17 kelas dengan jumlah guru, 36 .

Dari 17 kelas secara umum memiliki fasilitas: ventilasi, 
meubeler, dan satu papan tulis. Sekolah memiliki lahan $21.000 \mathrm{~m} 2$.

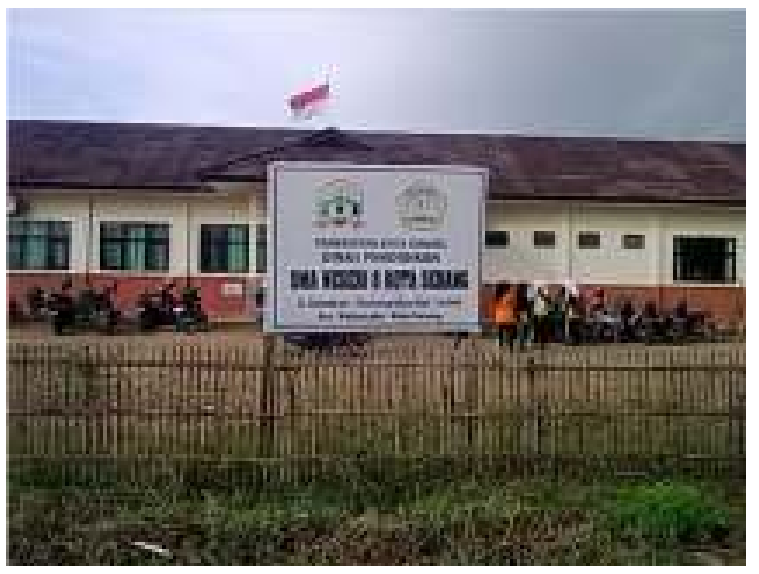

Gambar 2

Gedung Depan Sekolah, Maret 2016

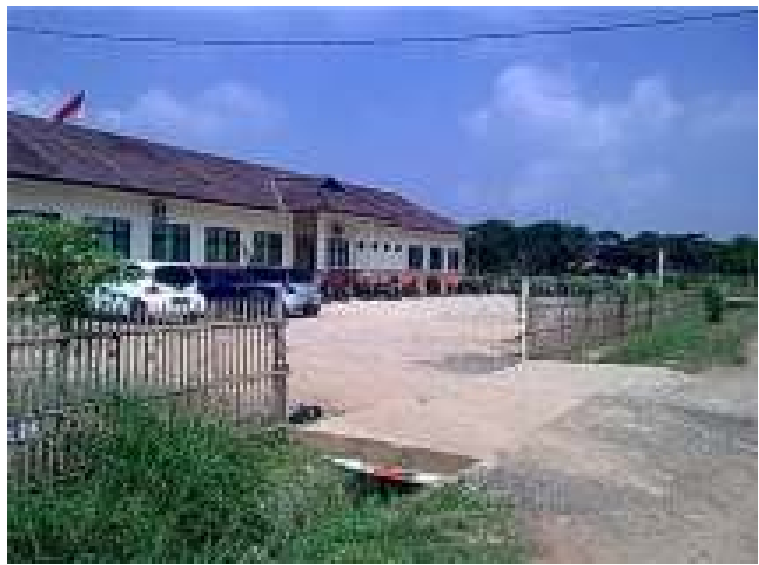

Gambar 3

SMAN 8 Serang Terletak di Kecamatan

Walantaka

\section{Hasil}

Sekolah ini berusaha mencapai gelar Adiwiyata, program - program yang diperuntukan percepatan menuju Adiwiyata sudah mulai dilakukan. Maka dari hasil angket ini dapat dilihat sebagai berikut:Jumlah angket sebanyak 50 eksemplar disebar di SMA Negeri 8 Kota Serang. Pada lembar angket pertama, Didapatkan data dalam grafik 1, ditanyakan kepada siswa, tentang apakah mereka mengerti tentang program Adiwiyata. Dari hasil angket tersebut, kita dapat melihat bahwa setengah dari siswa sekolah SMA 8 Serang sudah tidak asing lagi dengan istilah Adiwiyata. Tetapi masih ada siswa yang tidak pernah mendengar tentang Adiwiyata. Melihat kondisi ini, sebaiknya ada sosialisasi kepada para siswa, menjelaskan tentang target sekolah SMA Negeri 8 Kota Serang untuk menjadi sekolah Adiwiyata. Kemudian dari angket lembar ke 1, berisi kondisi pengetahuan siswa tentang lingkungan hidup saat ini dan untuk waktu yang akan datang.

Ini dapat kita lihat pada data nomor 1 dan 2 di grafik 1. Pada kondisi saat ini siswa berusaha untuk menjaga kebersihan kelas, selalu membuang sampah pada tempatnya dan ikut memelihara kebersihan lingkungan sekolah mendapat lebih dari $80 \%$ jawaban Ya.

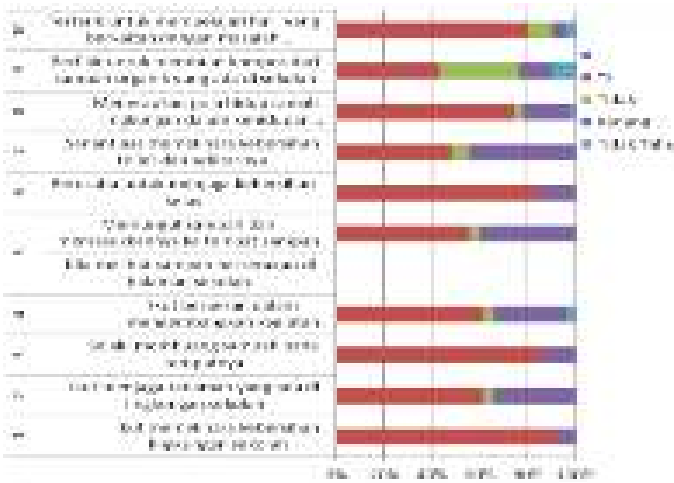

Grafik 1

Kondisi Siswa saat ini berkaitan dengan pengetahuan Tentang Adiwiyata

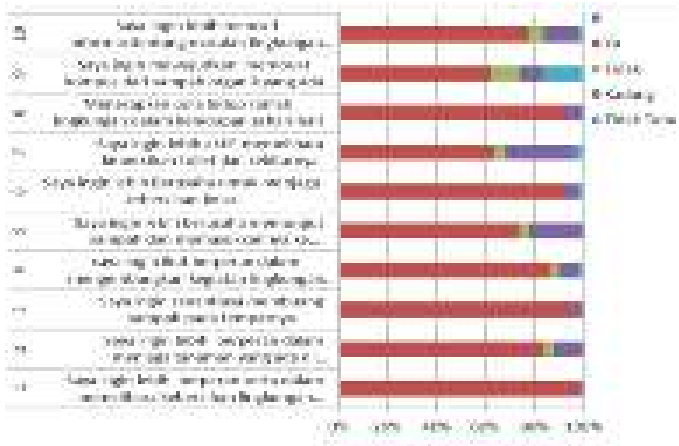

Grafik 2

Kondisi Siswa saat ini berkaitan dengan motivasi masa yang akan datang

Hasil angket menunjukan bahwa siswa SMA Negri 8 Serang memiliki keinginan untuk menjadikan sekolah mereka bergelar Adiwiyata. Nilai 
tertinggi dapat dilihat dari nomor 1 yaitu hampir 100\% ingin lebih berperan. Pada pertanyaan nomor 5 , pada angket kondisi saat ini, siswa $55 \%$ bersedia memungut sampah- sampah yang berserakan di sekolah dan membuang pada tempatnya, artinya $45 \%$ siswa belum tergugah untuk memungut, tetapi pada angket yang akan datang, No $3,90 \%$ siswa menjawab ingin memungut sampah dan membuangnya ke tempat sampah. Ada perbedaan 35\% pada perubahan behavior siswa. No 8: tentang hidup ramah lingkungan 95\% siswa menjawab ingin lebih berperan aktif.
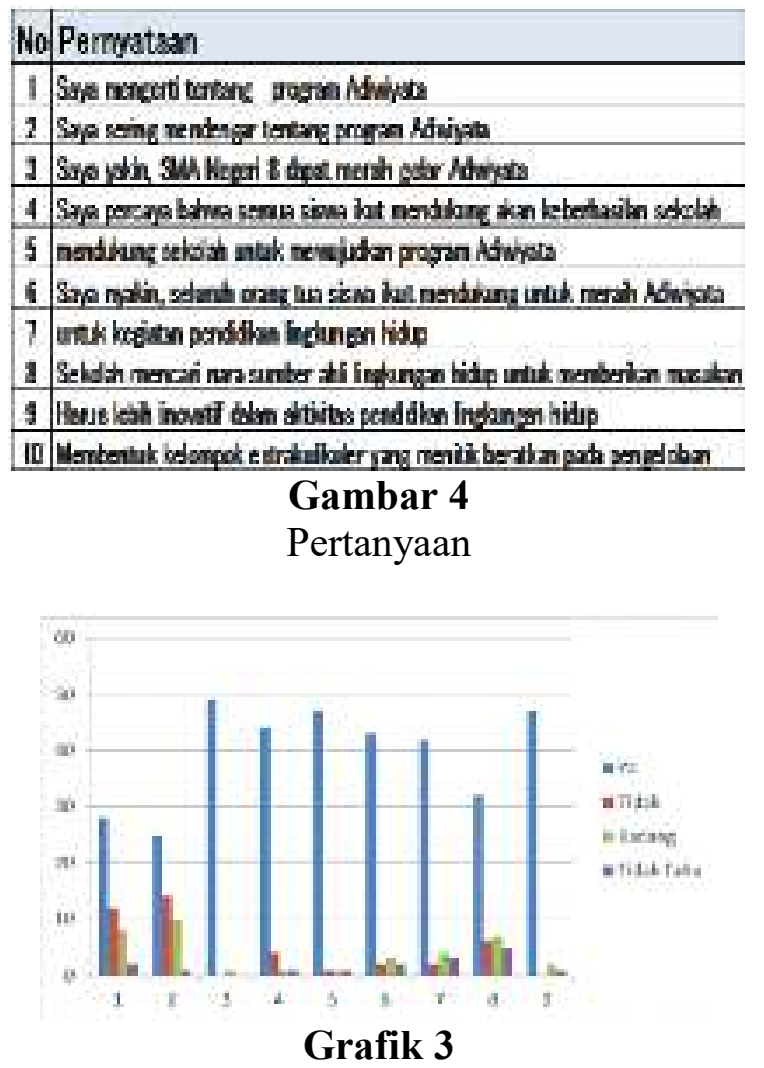

Hasil angket tentang Adiwiyata

Program Adiwiyata merupakan program yang membentuk segenap warga sekolah menjadi karakter yang peduli terhadap lingkungan hidup. Menciptakan sekolah yang bersih, sehat, indah dan memiliki etika dan estetika. Dari rata-rata hasil angket yang disebar rmenunjukan bahwa kesadaran siswa akan pemanfaatan energy sudah sangat baik. Ini terbukti sebagian besar memilih jawaban ya (yes) untuk pertanyaan yang berhubungan dengan penghematan energi kecuali pada pertanyaan no 8 (penggunaan mybag) dan no 10 (menampung air hujan untuk menyiram tanaman). Distribusi jawaban dapat dilihat pada grafik 4 di bawah ini.

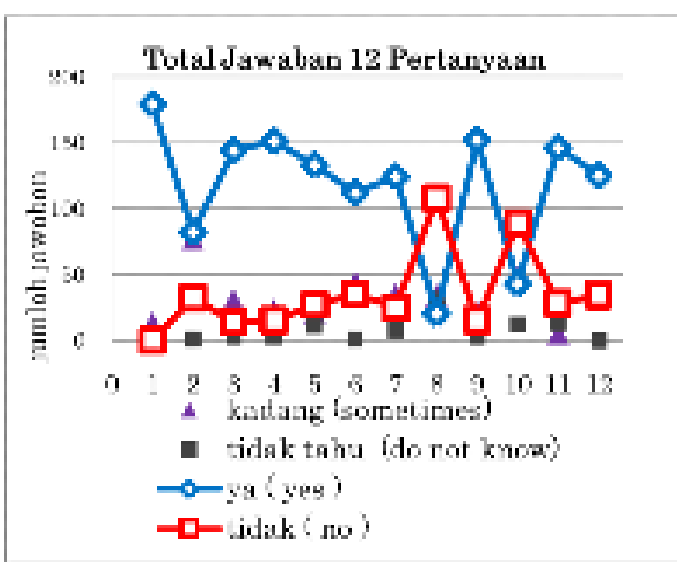

Grafik 4

Penyebaran Jawaban 12 Pertanyaan

Dari 12 pertanyaan tersebut, dapat dikelompokkan menjadi 3 group. Group A adalah jawaban yang menunjukan bahwa tingkat kesadaran siswa terhadap penggunaan energi cukup tinggi, group B adalah yang memberi jawaban antara $\mathrm{Ya}$ dan Tidak. Sedang kan group C hampir 50\% menjawab tidak

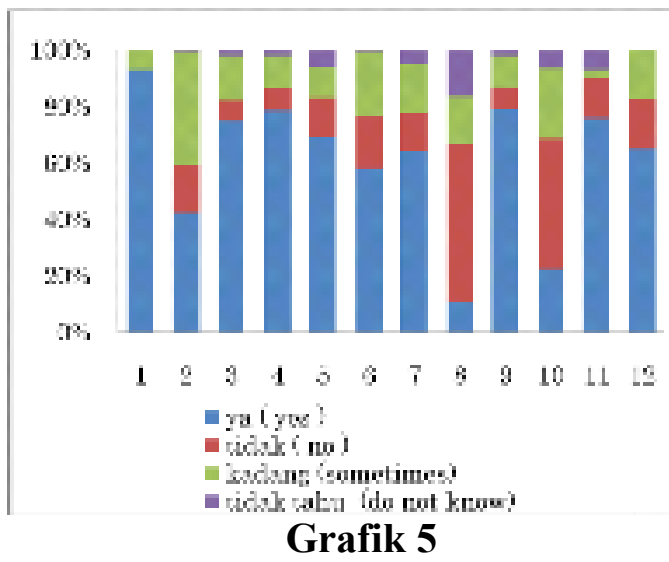

Persentase Jawaban 12 Pertanyaan

Pada grafik 5 terlihat bahwa jawaban ya (yes) pada pertanyaan 1 , $3,4,5,6,7,9,11$ dan 12 cukup tinggi 
(diatas $75 \%$ ). Seperti pada pertanyaan no 1 "Apakah mereka mematikan TV ketika tidak ada yang menonton. Diatas $75 \%$ rata-rata menjawab mematikan $\mathrm{TV}$ (grafik 4).

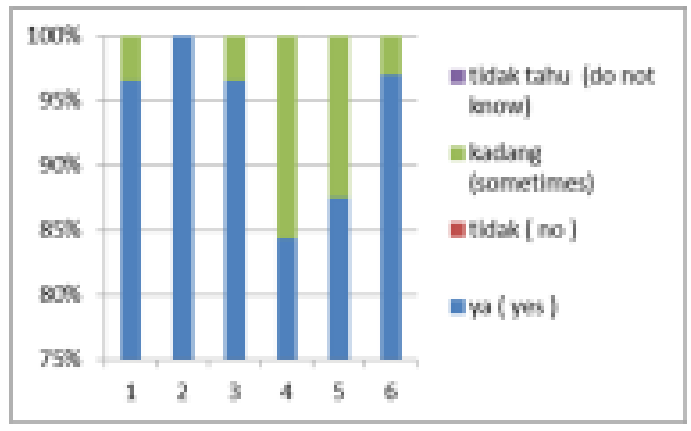

Grafik 6

Penyebaran Jawaban Pertanyaan no 1 di tiap kelas (Mematikan TV Jika Tidak Ada Yang Menonton)

Pada pertanyaan no 2 mengenai mematikan semua peralatan elektronik sebelum tidur, 82 siswa (43\%) menjawab ya, 32 siswa (17\%) menjawab tidak dan 77 siswa (40 \%) menjawab kadang kadang. Pada pertanyaan no 2 tersebut jumlah siswa yang menjawab ya dengan yang menjawab kadang kadang (Ya dan Tidak) cukup seimbang. Hal ini menarik, karena mereka mengerti dan tahu untuk mematikan peralatan elektronik sebelum tidur tetapi ada kecenderungan faktor kebiasaan yang berbeda sehingga jawaban kadang kadang cukup tinggi.

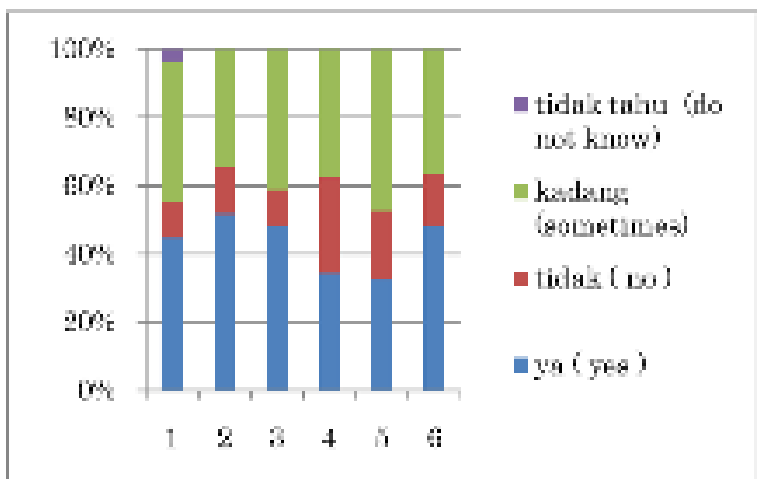

Grafik 7

Penyebaran jawaban pertanyaan no 2 di tiap kelas (Mematikan Peralatan Elektonik Sebelum Tidur)
Untuk pertanyaan no 8 mengenai penggunaan mybag ketika berbelanja, 108 siswa (56 \%) mengatakan tidak menggunakan atau memakai plastik dari toko jika berbelanja. Distribusi jawaban mengenai penggunaan Mybag dapat dilihat pada grafik 7. Hampir semua kelas survey sebagian besar menjawab tidak (no).

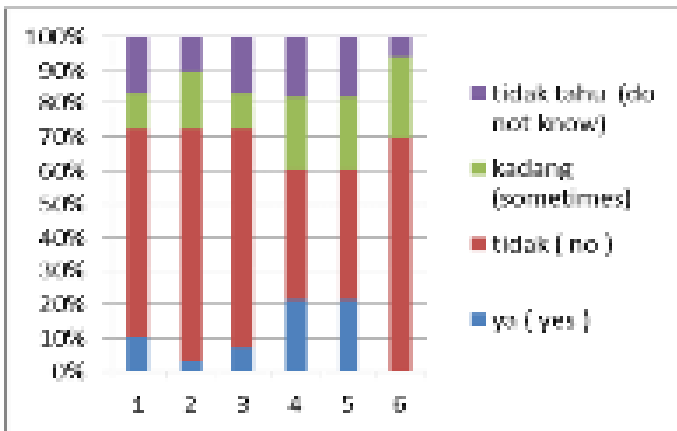

Grafik 8

Penyebaran jawaban pertanyaan no 8 di tiap kelas (Pemakaian Mybag)

Di Indonesia dan kota Serang khususnya, penggunaan mybag belum populer dan baru mulai disosialisasikan. Meskipun begitu beberapa mini market dan satu departemen store di kota Serang sudah menerapkan kantong plastik berbayar dan tanpa kantong plastik. Jumlah mini market dan departement store tersebut masih sangat kecil jika dibandingkan dengan jumlah mini market, dept. store, toko, warung dan pasar yang belum menerapkan program mybag dan kantong plastik berbayar di kota Serang. Memang pada saat ini belum begitu terlihat pengaruhnya. Dari survey terhadap siswa SMAN 8 Serang mengenai penggunaan mybag ketika berbelanja terdapat 20 siswa $(10 \%)$ yang mengatakan ya dan 33 siswa (17\%) yang mengatakan kadang kadang. Itu sudah sangat baik sebagai permulaan program mybag.

Untuk pertanyaan no 10 mengenai menampung air hujan untuk menyiram tanaman, 89 siswa 
(46\%) mengatakan tidak dan 48 siswa (25\%) mengatakan kadang kadang. Distribusi jawaban mengenai pertanyaan no 10 tiap kelas dapat dilihat pada grafik 8. Berkaitan dengan materi air, membutuhkan pendidikan lingkungan untuk siswa, tentang penghematan air, sehingga siswa dapat lebih memahami pentingnya penghematan air.

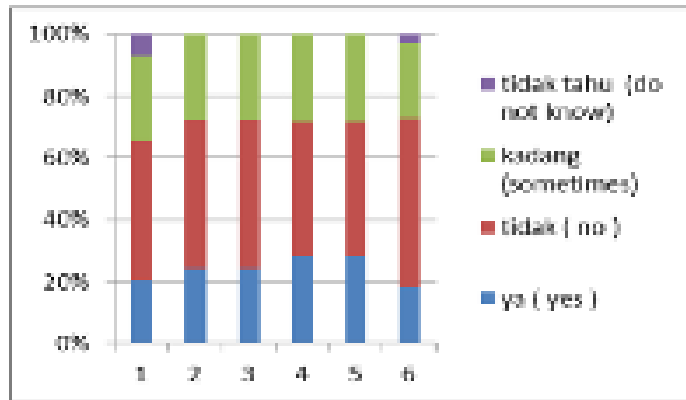

Grafik 9

Penyebaran jawaban pertanyaan no 8 di tiap kelas (Menampung air hujan untuk menyiram tanaman di rumah)

Menampung air untuk keperluan sehari hari bukan atau belum menjadi budaya sebagian besar warga Kota Serang khususnya dan Indonesia pada umumnya. Budaya tersebut dimiliki oleh beberapa masyarakat Indonesia yang tinggal dipesisir pantai dan pulau-pulau kecil di Indonesia. Kondisi sebagian besar alam Indonesia memiliki 2 musim dimana saat musim hujan jumlah air sangat melimpah. Penampungan air hujan di Indonesia umumnya dilakukan pada danau alam, danau buatan dan waduk. Pemerintah lebih tertarik terhadap program pembuatan biopori pada tanah untuk menjaga kesuburan dan air tanah.

Bila melihat dari hasil angket pertama, kita dapat menyimpulkan bahwa masih dibutuhkannya pendidikan lingkungan hidup bagi siswa, terutama kesadaran siswa dalam penggunaan mybag sebagai salah satu bentuk peran serta siswa menekan peningkatan sampah kantong plastik. Pembiasaan siswa mengunakan mybag sebaiknya di ajarkan kepada siswa tentang manfaat penggunaannya.

Dalam kehidupan manusia, tidak terlepas dari penggunaan energi. Setiap hari ada banyak energi yang kita butuhkan untuk kelangsungan hidup. Berbagai upaya dilakukan oleh manusia untuk menemukan sumber energy baru. Tetapi suatu saat energi yang tak terbarukan akan habis jika digunakan terus menerus.

Mempelajari tentang pengembangan dan pemanfaatan energi merupakan bagian dari kurikulum pendidikan lingkungan hidup di setiap jenjang pendidikan. Energi merupakan hal yang sangat penting untuk dipelajari, karena dalam penggunaannya akan menyangkut kepada banyak hal. Salah satu adalah dampak dari penggunaan energi tersebut. Bagaimana kita menggunakan energi, dan bagaimana kita dapat berhemat energi dalam kehidupan sehari-hari.

Banyak individu dalam masyarakat kurang paham cara memanfaatkan energy. Oleh sebab itu pendidikan lingkungan hidup penting untuk dipelajari oleh seluruh lapisan masyarakat, terutama oleh siswa sekolah.

Siswa sekolah diharapkan akan menjadi manusia dewasa yang dapat mengubah pemikiran dan perilaku di dalam keluarga dirumah dan masyarakat. Menurut suatu penelitian dikatakan bawah anakanak dapat bertindak sebagai katalis untuk mempengaruhi perilaku bijak orang tua mereka dalam berperilaku ramah lingkungan, yaitu memiliki pengaruh antar generasi dalam keluarga dan masyarakat.

Sekolah SMA Negeri 8 Serang adalah termasuk sekolah Negeri yang masih muda, Didirikan tahun 2011. Tetapi SMA Negeri 8 berusaha untuk menjadi sekolah Adiwiyata. Dari 
hasil angket yang didapat, menunjukan bahwa siswa SMA Negeri 8 adalah siswa yang memiliki kebiasaan hemat energy. Point-point yang harus diperhatikan guna percepatan perwujudan Sekolah Adiwiyata:

a. Kebijakan Berwawasan Lingkungan dengan memberi perhatian pada:

1) Kurikulum di sekolah : visi, misi sekolah dan struktur kurikulum yang memuat kebijakan perlindungan dan pengelolaan lingkungan hidup (PPLH).

2) Rencana Kegiatan dan Anggaran Sekolah (RKAS), yang memuat program dalam upaya perlindungan dan pengelolaan lingkungan hidup.

b. Pelaksanaan Kurikulum Berbasis Lingkungan Pelaksanaan kurikulum berbasis lingkungan ini memberi perhatian pada:

1) Tenaga pendidik memiliki kompetensi dalam mengembangkan kegiatan pembelajaran lingkungan hidup.

2) Peserta didik melakukan kegiatan pembelajaran tentang perlindungan dan pengelolaan lingkungan hidup.

c. Kegiatan Lingkungan Berbasis Partisipatif

1) Melaksanakan kegiatan guna perlindungan dan pengelolaan lingkungan hidup yang terencana bagi warga sekolah.

2) Menjalin kemitraan dalam rangka perlindungan dan pengelolaan lingkungan hidup dengan berbagai pihak (masyarakat, pemerintah, swasta, media, sekolah lain).

d. Pengelolaan Sarana Pendukung Ramah Lingkungan.

1) Ketersediaan sarana prasarana pendukung yang ramah lingkungan.

2) Peningkatan kualitas pengelolaan dan pemanfaatan sarana dan prasarana yang ramah lingkungan

\section{E. SIMPULAN DAN SARAN}

Pelaksanaan program kerja untuk pencapaian gelar Adiwiyata berpengaruh terhadap pengetahuan dan pola siswa dalam kehidupan sehari-hari. Tentunya masih banyak hal yang harus dicapai terutama hal yang menyangkut pola hidup ramah lingkungan. Dari kondisi kebiasaan siswa saat ini, kebiasaan siswa dalam pemanfaatan energy dan pengetahuan tentang adiwiyata, sebagai modal dasar yang nampaknya sudah bisa menjadi dasar yang kuat dalam percepatan Adiwiyata. Dalam komponen Adiwiyata, terdapat point kebijakan berwawasan lingkungan, pelaksanaan kurikulum berbasis lingkungan, kegiatan lingkungan dan pengelolaan sarana pendukung ramah lingkungan. Hal ini semua dimiliki oleh SMA 8 Serang. Sikap yang positif dan memiliki kemauan untuk masa yang akan datang, menjadi lebih ramah ling kungan Ini dapat kita lihat bahwa lebih dari 6 pertanyaan menjawab Ya $80 \%$.Yang paling tinggi adalah "Lebih ingin berperan serta memelihara lingkungan. Maka dapat disimpulkan bahwa siswa memiliki kebiasaan penghematan energy dan memiliki keinginan agar sekolah SMA Negeri 8 dapat menjadi sekolah yang meraih gelar Adiwiyata Program.

Untuk mewujudkan hal tersebut, maka perjuangan segenap masyarakat sekolah dan juga peran serta orang tua murid, akan ikut menentukan keberhasilan ini.

\section{DAFTAR PUSTAKA}

$\begin{array}{ccc}\text { Amirul } & \text { Mukminin, } & \text { Strategi } \\ \text { Pembentukan } & \text { Karakter } & \text { Perduli } \\ \text { Lingkungan } & \text { di } & \text { sekolah } \\ \text { Adiwiyata } & & \end{array}$

Barbara

Bader, "MemegangLingkungan": 
Membuat Ruang untuk Mendukung Anak Belajar Lingkungan di abad ke-21.

Fakultas Ilmu Sosial Universitas Negeri Malang

Karen Malone, Sekolah berkelanjutan: Membuat Efisiensi Energi Gaya Hidup Prioritas.

Ken Purnell, Mark Sinclair \& Anna Gralton. Environmental Education Energy.

Monalisa, Program Adiwiyata Dalam Pengelolaan Lingkungan Sekolah di SMP Negeri 24 Padang.2013.Vol 1 No 01.

Reni Indrawati, Implementasi Pendidikan Karakter pada program Adiwiyata Melalui Kegiatan Lingkungan Berbasis Partisipatif di SMK negeri 1 Turen.

Sumarlin, Rini. Persepsi dan Kepedulian Siswa Terhadap Pengelolaan Lingkungan Sekolah melalui Program Adiwiyata. 2013.

Universitas Muhammadiyah Surakarta

Untung Wahyuhadi, Pengelolaan Sekolah Adiwiyata di SMK Negeri 1 Salatiga.

Yanti Dwi Rahmah, Implementasi Program Sekolah Adiwiyata (Studi pada Sekolah Dasar Negeri Manukan Kulon III/540 Kota Surabaya). 